Asthma

\title{
The use of inhaled corticosteroids during childhood: plus ça change...
} G Russell

\section{Commentary on the paper by Masoli et al (see page 902)}

nhaled corticosteroid therapy (ICT) has a long and for the most part honourable history in the management of asthma. Introduced in an attempt to minimise the side effects associated with systemic treatment, early trials with nebulised hydrocortisone showed little if any added benefit, ${ }^{1}$ but with the introduction of beclomethasone dipropionate, ${ }^{2}$ ICT rapidly assumed a central rôle in the management of asthma, transforming the lives of millions of sufferers.

Early studies were reassuring, but it soon became apparent that ICT did have measurable systemic effects on the hypothalamo-pituitary-adrenal axis, ${ }^{3}$ although there was little evidence that these translated into clinically significant problems, overt corticosteroid toxicity being a rare and apparently idiosyncratic reaction. ${ }^{4}$ Worries about the very real effects of ICT on growth ${ }^{5}$ have been largely banished by the demonstration of normal adult height at follow up. ${ }^{6}$ Posterior subcapsular cataract formation has been reported in children on ICT, but mainly in children who have also received systemic corticosteroids. ${ }^{78}$ Local reactions such as oral candidiasis and hoarseness occur on ICT, ${ }^{10}$ but usually respond to simple measures such as mouth washing and the use of a spacer.

Thus, in recommended doses, ICT has had an excellent safety record, ${ }^{11}$ but encouraged by reports of the apparent safety of high dose ICT in adults, ${ }^{12}$ paediatricians became increasingly bold in ignoring the manufacturers' dosage recommendations, sometimes using doses that might have been more appropriate in the stable than the paediatric ward. Alas, it was all to end in tears. Several alarming reports of symptomatic adrenal insufficiency in children receiving high dose inhaled corticosteroid therapy appeared in the literature, including two in Archives. ${ }^{13}{ }^{14}$ The second of these reported the results of a survey of British paediatric respirologists and endocrinologists, ${ }^{14}$ who identified 28 children with acute adrenal insufficiency, of whom 23 presented with hypoglycaemia. The authors later became aware of five further British cases. $^{15}$ Although other forms of ICT were occasionally involved, by far the most frequently implicated drug in this series was fluticasone, a finding for which there are three possible explanations.

Firstly, despite its well established efficacy and safety at the recommended dose of up to $200 \mu \mathrm{g}$ per day, fluticasone might be more toxic at higher doses, ${ }^{16}$ and I explored possible mechanisms for this in a commentary ${ }^{17}$ on Todd's paper.

Secondly, severe adrenal insufficiency might be an idiosyncratic reaction to fluticasone, similar to the toxic effects seen in the occasional patient on other forms of ICT. ${ }^{418}$

Thirdly, encouraged by reports of the safety of fluticasone in recommended doses, practitioners might have preferred high dose fluticasone to other forms of ICT in children who were unresponsive to normal doses, producing an entirely spurious association between fluticasone and adrenal crisis. There is evidence to support this hypothesis. ${ }^{19}$ Unfortunately, in the absence of detailed information on national prescribing practice, those wishing to relate the incidence of adrenal crisis to the type and dose of ICT will find in Todd's paper a set of reasonably accurate numerators, but no denominators, and may well be left wondering why this problem was not seen during the many years when beclomethasone and budesonide were the only forms of ICT available in the UK, and when alternative therapies such as long acting $\beta_{2}$ agonists and leukotriene inhibitors were not available to help constrain the ICT dose.

It was against this background that Masoli and colleagues ${ }^{20}$ undertook a systematic review of the dose-response of fluticasone in children. Not surprisingly, given the unwillingness of manufacturers to sponsor trials of their drugs at greater than recommended doses, they found only one efficacy trial in which a daily dose of $400 \mu \mathrm{g}$ was used, and this showed only slight added benefit over a daily dose of $200 \mu \mathrm{g}$. Unfortunately, although it is clear that the dose-response curve is beginning to flatten between 200 and $400 \mu \mathrm{g}$, its shape beyond that point is unknown, although it is a reasonable assumption that the therapeutic gain at higher doses will be small.

What are the implications of this report for the practitioner faced with a child who is unresponsive to recommended doses of ICT? The initial reaction is unrelated to dose-response curves. When a child fails to respond to a treatment that is effective in almost everyone else with the same condition, the case should be reviewed to ensure that the diagnosis is correct, that relevant triggers are being avoided, that compliance with therapy is satisfactory, and that full use has been made of alternative treatments.

The review by Masoli and colleagues ${ }^{20}$ suggests only minor therapeutic gain from using fluticasone in doses $>200 \mu \mathrm{g}$ per day. However, it must be remembered that Masoli and colleagues ${ }^{20}$ analysed observations made in the context of clinical trials, a situation that bears only a passing resemblance to real life clinical practice. In clinical trials, carefully selected, trained, and compliant patients follow elaborate protocols involving detailed monitoring of both adherence and response to treatment; even so, we know that compliance falls to less than $50 \%$ in prolonged trials. ${ }^{21}$

In clinical practice compliance is miserably poor. We know that only about three quarters of the prescribed medication is given, even when parents know they are being monitored, ${ }^{22}$ and only one in six patients receive enough repeat prescriptions to suggest that they might be taking their prophylactic treatment regularly. ${ }^{23}$ Thus the real life patient seldom complies fully with treatment and may even contrive not to do so, $^{24}$ may be incompetent or careless about inhaler technique, ${ }^{24}$ and may be using any one of a wide variety of inhaler devices delivering a varying proportion of administered drug to the airways. ${ }^{25}$ It is therefore reasonable to conclude that even if fluticasone is prescribed in a dose of $200 \mu \mathrm{g}$ twice daily-that is, at twice the upper recommended dose for children, the amount actually taken will be appreciably less, and indeed is likely to be within recommended limits. Compliance problems probably explain the disparity between the results of formal trials, which tell us that there is little to be gained from using high dose ICT, and the obvious benefit experienced by many patients when such treatment is used.

The second issue explored by Masoli and colleagues $^{20}$ is the capacity of various doses of fluticasone to produce 
adrenal suppression. In daily doses within the recommended range, all forms of ICT have an excellent safety record in children. Much less is known about the safety of higher doses. In the case of fluticasone, Masoli and colleagues $^{20}$ found reports of adrenal suppression in an appreciable number of children receiving daily doses of $400 \mu \mathrm{g}$ and above. Poor compliance might also underlie at least some instances of acute adrenal failure, if sufficient ICT is taken to cause adrenal suppression, and then reduced or withdrawn before adrenal recovery can occur.

Does this mean that fluticasone should be completely avoided at doses $>200 \mu \mathrm{g}$ per day? I think not. Fluticasone is currently used in higher than recommended doses in large numbers of children with difficult asthma, in whom it is frequently effective, and it would clearly be wrong to deny them effective treatment. There is however a good case for ensuring that compliance and response are monitored carefully, and that the high dose is continued only if there is clear evidence of benefit. There is also a reasonable case for suggesting that such patients should carry steroid cards or wear a warning bracelet, but need anything further be done?

I would argue, as I have done previously, ${ }^{17}$ that patients on exceptionally high doses of ICT should have an adrenal function test performed, the low dose ACTH test ${ }^{26}$ being the most widely used, although it has been suggested that the corticotrophin releasing hormone test provides a more accurate assessment of the entire hypothalamopituitary-adrenal axis. ${ }^{27}$ However, there are problems with this apparently simple suggestion.

The first is the definition of "exceptionally high doses". The review by Masoli and colleagues ${ }^{20}$ could be used to justify a cut-off point of $\geqslant 400 \mu \mathrm{g}$ per day, but we would need to build extensions to our endocrinology investigation units if we were to test all such children. My previous suggestion ${ }^{17}$ of a cut-off point of $\geqslant 1000 \mu \mathrm{g}$ per day was based on the apparent danger of such a dose ${ }^{14}$ but the same evidence could be used to justify a cut-off of $\geqslant 500 \mu \mathrm{g}$ per day. Given that $500 \mu \mathrm{g}$ is $2 \frac{1}{2}$ times the recommended dose, and somewhat higher than the $400 \mu \mathrm{g}$ dose identified as potentially dangerous in Masoli and colleagues' review, ${ }^{20}$ this is perhaps a more suitable line at which to start worrying. For beclomethasone and budesonide, the comparable figure would be $1000 \mu \mathrm{g}$ per day.

The second problem lies in defining clinically significant depression of adrenal function-that is, function so impaired as to pose a threat to the child, justifying the withdrawal of a significant part of the child's asthma medication. Biochemical evidence of impaired adrenal function on ICT has been shown in numerous studies, but until recently has not been associated with clinical features of hypoadrenalism. Care must therefore be taken not to over-interpret the results of adrenal function tests, resulting in the withdrawal of effective therapy.

Although the systematic review by Masoli and colleagues ${ }^{20}$ provides us with a useful overview of some of the evidence on which we base our clinical practice, its focus was restricted to clinical efficacy and adrenal suppression, and did not address the effects on collagen synthesis and bone metabolism that may yet turn out to be the most important side effects of ICT.

Loss of bone mineral density is a long established side effect of oral corticosteroid therapy for asthma, ${ }^{28}$ so it was hardly surprising that high dose ICT was shown to have similar metabolic effects in both adults ${ }^{29}$ and children. ${ }^{30}{ }^{31}$ In normal doses, ICT appears to have no adverse effect on bone density in children. ${ }^{32}{ }^{33}$ However, even at normal doses there are biochemical changes, ${ }^{34} 35$ which we ignore at our peril, just as we previously ignored suppressive effects on the hypothalamo-pituitary axis. Indeed, there are some hints that these changes may be of clinical significance. Children on ICT have been shown to have a dose related risk of fractures, ${ }^{36}$ and although in this study the excess risk disappeared after adjustment for indicators of asthma severity (and one expects the ICT dose to be related to asthma severity), it is difficult to escape the worrying possibility that ICT rather than asthma was the true culprit, particularly as it is known that bone mineral density is normal in asthmatic children before starting ICT. ${ }^{37}$

These effects on bone are particularly worrying because they are cumulative and because asthma is a chronic condition, so that we may be producing a generation of asthmatic children, particularly girls, who having failed to achieve normal peak bone mineral density at the end of puberty, may continue to take high dose ICT for many further years, leading to gradual but sustained bone demineralisation, greatly enhancing the risk of postmenopausal (or even pre-menopausal) osteoporosis.

Against this background, should the guidelines $^{38}$ for the management of childhood asthma be changed? In fact, there's nothing wrong with the guidelines; what's wrong is our failure to observe them. We should be much more assiduous in applying the long standing dogma that the best dose of any drug is the lowest effective dose, we should focus much more on the importance of stepping down as well as stepping up the dosage of ICT, and we should use high dose ICT only when all else has failed. But none of that is new, it's what we should have been doing since 1974 .

Arch Dis Child 2004;89:893-895

doi: 10.1136/adc.2004.049577

Correspondence to: $\operatorname{Dr} \mathrm{G}$ Russell, Royal Aberdeen Children's Hospital, Cornhill Road, Aberdeen AB25 2ZD, UK; libra@ifb.co.uk

\section{REFERENCES}

1 Cotes PM, McLean A, Sayer JB. Absorption of inhaled hydrocortisone. Lancet 1954;ii:807-8

2 Brown HM, Storey G, George WH.

Beclomethasone dipropionate: a new steroid aerosol for the treatment of allergic asthma. BMJ 1972;1:585-90.

3 Wyatt R, Waschek J, Weinberger $M$, et al. Effects of inhaled beclomethasone dipropionate and alternate-day prednisone on pituitary-adrenal function in children with chronic asthma. N Engl J Med 1978;299:1387-92.

4 Priftis K, Everard ML, Milner AD. Unexpected side-effects of inhaled steroids: a case report. Eur J Pediatr 1991;150:448-9.

5 Wolthers OD. Long-, intermediate- and short-term growth studies in asthmatic children treated with inhaled glucocorticosteroids. Eur Respir J 1996;9:821-7.

6 Agertoft L, Pedersen S. Effect of long-term treatment with inhaled budesonide on adult height in children with asthma. N Engl J Med 2000;343:1064-9.

7 Abuekteish F, Kirkpatrick JN, Russell G. Posterior subcapsular cataract and inhaled corticosteroid therapy. Thorax 1995;50:674-6.

8 Covar RA, Leung DY, McCormick D, et al. Risk factors associated with glucocorticoid-induced adverse effects in children with severe asthma. J Allergy Clin Immunol 2000;106:651-9.

9 Toogood JH, Jennings B, Greenway RW, et al. Candidiasis and dysphonia complicating beclomethasone treatment of asthma. J Allergy Clin Immunol 1980;65:145-53.

10 Shaw NJ, Edmunds AT. Inhaled beclomethasone and oral candidiasis. Arch Dis Child 1986;61:788-90.

11 Russell G. Inhaled corticosteroid therapy in children: an assessment of the potential for side effects. Thorax 1994;49:1185-8.

12 Smith MJ, Hodson ME. High-dose beclomethasone inhaler in the treatment of asthma. Lancet 1983:1:265-9.

13 Patel L, Wales JK, Kibirige MS, et al Symptomatic adrenal insufficiency during inhaled corticosteroid treatment. Arch Dis Child 2001;85:330-4.

14 Todd GR, Acerini CL, Ross-Russell R, et al. Survey of adrenal crisis associated with inhaled corticosteroids in the United Kingdom. Arch Dis Child 2002;87:457-61.

15 Todd GR. Adrenal crisis due to inhaled steroids is underestimated. Arch Dis Child 2003;88:554-5.

16 Lipworth BJ. Systemic adverse effects of inhaled corticosteroid therapy: a systematic review and meta-analysis. Arch Intern Med 1999;159:941-55.

17 Russell G. Inhaled corticosteroids and adrena insufficiency. Arch Dis Child 2002;87:455-6.

18 Hollman GA, Allen DB. Overt glucocorticoid excess due to inhaled corticosteroid therapy. Pediatrics 1988;81:452-5.

19 Devoy M. Use of inhaled corticosteroids in children. Arch Dis Child 2003;88:461.

20 Masoli $M$, Weatherall M, Holt S, et al. Systematic review of the dose-response relation of inhaled fluticasone propionate. Arch Dis Child 2004;89:902-7. 
21 Jonasson G, Carlsen KH, Mowinckel P. Asthma drug adherence in a long term clinical trial. Arch Dis Child 2000:83:330-3.

22 Gibson NA, Ferguson AE, Aitchison TC, et al. Compliance with inhaled asthma medication in preschool children. Thorax 1995:50:1274-9

23 Warner JO. Review of prescribed treatment for children with asthma in 1990. BMJ 1995;311:663-6.

24 Everard ML. Role of inhaler competence and contrivance in "difficult asthma". Paediatr Respir Rev 2003;4:135-42

25 Everard ML. Guidelines for devices and choices. J Aerosol Med 2001;14(suppl 1):S59-64.

26 Patel L, Clayton PE. Clinical usefulness of the low dose ACTH test. J Endocrinol Invest 1999;22:401-4.

27 Pescollderungg L, Radetti G, Gottardi E, et al. Systemic activity of inhaled corticosteroid treatment in asthmatic children: corticotrophin releasing hormone test. Thorax 2003;58:227-30.

28 Ruegsegger P, Medici TC, Anliker M.

Corticosteroid-induced bone loss. A longitudinal study of alternate day therapy in patients with bronchial asthma using quantitative computed tomography. Eur J Clin Pharmacol

1983;25:615-20

29 Toogood JH, Jennings B, Hodsman AB, et al. Effects of dose and dosing schedule of inhaled budesonide on bone turnover. J Allergy Clin Immunol 1991 88:572-80.

30 Sorva R, Turpeinen M, Juntunen-Backman K, et al. Effects of inhaled budesonide on serum markers of bone metabolism in children with asthma. J Allergy Clin Immunol 1992;90:808-15.

31 Allen HD, Thong IG, Clifton-Bligh P, et al. Effects of high-dose inhaled corticosteroids on bone metabolism in prepubertal children with asthma. Pediatr Pulmonol 2000;29:188-93.

32 Roux C, Kolta S, Desfougeres JL, et al. Long-term safety of fluticasone propionate and nedocromil sodium on bone in children with asthma. Pediatrics 2003; 111 :e706-13.

33 Bahceciler NN, Sezgin G, Nursoy MA, et al. Inhaled corticosteroids and bone density of children with asthma. J Asthma 2002;39:151-7.

34 Heuck C, Heickendorff L, Wolthers OD. A randomised controlled trial of short term growth and collagen turnover in asthmatics treated with inhaled formoterol and budesonide. Arch Dis Child 2000;83:334-9.

35 Kannisto $S$, Korppi $M$, Arikoski $P$, et al. Biochemical markers of bone metabolism in relation to adrenocortical and growth suppression during the initiation phase of inhaled steroid therapy. Pediatr Res 2002;52:258-62.

36 Van Staa TP, Bishop N, Leufkens HG et al. Are inhaled corticosteroids associated with an increased risk of fracture in children? Osteoporos Int Online First 21 February 2004, Article 83

37 Kelly HW, Strunk RC, Donithan M, et al. Growth and bone density in children with mild-moderate asthma: a cross-sectional study in children entering the Childhood Asthma Management Program (CAMP). J Pediatr 2003; 142:286-91

38 Anon. British guideline on the management of asthma. Thorax 2003;58(suppl 1):i1-94.

\section{IMAGES IN PAEDIATRICS}

doi: $10.1136 /$ adc. 2003.042168

\section{Gingivitis as probable source of a thoracic actinomycosis due to Actinomyces israelii and} Actinobacillus actinomycetemcomitans

A ctinomycosis is a chronic, granulomatous disease of cervicofacial (55\%), abdominal $(20 \%)$, or thoracic $(15 \%)$ location caused by Actinomyces israelii. ${ }^{1}$ It is often accompanied by copathogens such as Actinobacillus actinomycetemcomitans, which is also strongly associated with gingivitis. ${ }^{2}$

We report on a 9 year old boy who presented with a six week history of cough, weight loss, and malaise, but no fever. On physical examination he had right lower lobe dullness, and signs of gingivitis with tooth decay of the lower molars.

The erythrocyte sedimentation rate (ESR) was $110 \mathrm{~mm}, \mathrm{C}$ reactive protein (CRP) $91 \mathrm{mg} / \mathrm{l}$, leucocytes $14.7 \times 10^{9} / \mathrm{l}$ with a left shift. Chest $x$ ray examination showed right lower lobe consolidation with a pleural effusion; the pleural puncture was not diagnostic.

The patient improved on oral erythromycin; a follow up $x$ ray examination showed regression of the initial findings. Six weeks later he was readmitted with a painful soft tissue swelling over the right latero-dorsal thorax. $x$ Ray examination again showed right lower consolidation; bony destruction of one rib was suspected. An open biopsy of the swelling showed a chronic inflammatory process with pus containing Gram positive filiform rods resembling actinomyces. Culture was positive for $A$ israelii and $A$ actinomycetemcomitans. Although these organisms were not recovered from a gingival culture, $A$ actinomycetemcomitans was shown in three of four gingival lesions using

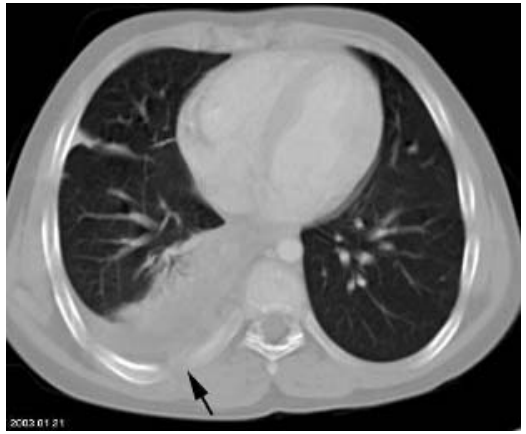

Figure 1 Thoracic CT scan showing right sided pleural effusion with pulmonary consolidation and erosion of rib (arrow).

specific hybridisation probes (IAIPado-Test 4.5). ${ }^{2}$ Postoperatively the patient became febrile. He made a full recovery with ampicillin/sulbactam for four weeks intravenously, followed by oral ampicillin/sulbactam for three months.

Actinomycosis is uncommon in Europe and can be mistaken for malignancy or other granulomatous or mixed anaerobic infections. Our patient probably aspirated the pathogens from his periodontal lesions. ${ }^{3}$ While $A$ israelii is susceptible to penicillin, tetracycline, erythromycin, and clindamycin in most cases, A actinomycetemcomitans may be resistant, ${ }^{45}$ as observed in our patient. In summary, adequate diagnostic procedures, debridement, and prolonged antibiotic therapy may be life saving in severe actinomycotic infections.
U Kordes, K Beutel

Department of Pediatric Hematology and Oncology, University Hospital Eppendorf, Hamburg, Germany G Cachovan

Department of Operative Dentistry and Periodontology, School of Dentistry, University Hospital Eppendorf, Hamburg, Germany

H Schäfer

Department of Pathology, University Hospital Eppendorf, Hamburg, Germany K Helmke

Department of Pediatric Radiology, University Hospital Eppendorf, Hamburg, Germany I Sobottka

Institute of Medical Microbiology and Immunology, University Hospital Eppendorf, Hamburg, Germany

Correspondence to: $\mathrm{Dr} U$ Kordes, Abteilung für Kinderhämatologie und -onkologie, Universitätsklinikum Hamburg-Eppendorf, Martinistr. 52, D-20246 Hamburg, Germany; kordes@uke.uni-hamburg.de

\section{References}

1 Russo TA. Agents of Actinomycosis. In: Mandell GLBJ, Dolin R, eds. Principles and practice of infectious diseases. Philadelphia: Churchill Livingstone, 2000:2645-54.

2 Wolf $\mathrm{H}$, Bolivar I. Mikrobiologische Diagnostik in der Parodontologie-Eine therapieunterstützende Maßnahme. Swiss Dent 2002;23:11-18.

3 Suzuki JB, Delisle AL. Pulmonary actinomycosis of periodontal origin. J Periodontol 1984;55:581-4.

4 Martin MV. Antibiotic treatment of cervicofacial actinomycosis for patients allergic to penicillin: a clinical and in vitro study. $\mathrm{Br} J$ Oral Maxillofac Surg 1985;23:428-34.

5 Morris JF, Sewell DL. Necrotizing pneumonia caused by mixed infection with Actinobacillus actinomycetemcomitans and Actinomyces israelii: case report and review. Clin Infect Dis 1994; 18:450-2. 